\title{
PHYTOCHEMICAL ANALYSIS AND ANTIOXIDANT PROPERTIES OF LEAF EXTRACTS OF CARICA PAPAYA
}

\section{NANDINI G ${ }^{1}$, GOPENATH TS ${ }^{2}$, NAGALAMBIKA PRASAD ${ }^{3}$, MURUGESAN KARTHIKEYAN ${ }^{4}$, ASHOK GNANASEKARAN ${ }^{4}$, RANJITH MS ${ }^{4}$, PRADEEP PALANISAMY ${ }^{5}$, KANTHESH M BASALINGAPPA ${ }^{1}$}

${ }^{1}$ Division of Molecular Biology, Faculty of Life Sciences, JSS Academy of Higher Education and Research, Mysuru, Karnataka, India. ${ }^{2}$ Department of Biotechnology, Faculty of Life Sciences, JSS Academy of Higher Education and Research, SS Nagara, Mysuru, Karnataka,

India. ${ }^{3}$ Department of Microbiology, Faculty of Life Sciences, JSS Academy of Higher Education and Research, SS Nagara, Mysuru, Karnataka, India. ${ }^{4}$ Department of Microbiology, Faculty of Medicine, Quest International University Perak, Malaysia. ${ }^{5}$ Faculty of Medicine, Universiti Kuala Lumpur Royal College of Medicine Perak (UniKL RCMP), Malaysia. Email: kantheshmb@jssuni.edu.in

Received: 06 July 2020, Revised and Accepted: 22 August 2020

ABSTRACT

Objective: The objective of the present study aimed at investigating the phytochemical and antioxidant properties of Carica papaya leaf extracts.

Methods: As phytochemicals are biologically active compounds and a powerful group of plant chemicals, believed to stimulate the immune system along with antioxidants, the molecules which hinder oxidation of other molecules by the process of inhibiting or by generating the oxidizing chain reactions and preventing diseases. The total phenolic content (TPC) was determined by Folin-Ciocalteu method and total flavonoid contents (TFC) were determined aluminum chloride method and antioxidant by 2,2,1-diphenyl-1-picrylhydrazyl method.

Results: The results of phytochemical screening revealed the presence of bioactive compounds such as alkaloid, carbohydrates, and amino acids and TPC and TFC varied among the different solvent extracts, in which methanolic extracts showed highest amount of phytochemicals and TPC and TFC and antioxidants compared to other solvents.

Conclusion: The isolation and purification of specific bioactive compound may account as natural and promising medicines in exploration of new drug. Keywords: Carica papaya Linn, Phytochemicals, Antioxidants.

(C) 2020 The Authors. Published by Innovare Academic Sciences Pvt Ltd. This is an open access article under the CC BY license (http://creativecommons. org/licenses/by/4. 0/) DOI: http://dx.doi.org/10.22159/ajpcr.2020.v13i11.38956

\section{INTRODUCTION}

Plants are considered to be the good source for the exploration and discovery of new pharmaceutical compounds as well as medicines, which can be the potential drug for humans as they act as intermediate for synthesis of useful drug [1]. Plants possess various phytochemicals with several bioactivities such as anti-inflammatory, antioxidant, and anticancer [2] and one among them such as Carica papaya is widely used in the treatment of many ailments in Ayurvedic as well as herbal and folk medicine.

C. papaya Linn, is an evergreen shrub or small tree, is a member of family Caricaceae, represented with four genera and four species in India. This plant originated in Southern Mexico and Costa Rica and distributed as a plantation crop in India, Sri Lanka, Hawaii, Australia, and in tropical and subtropical regions [3]. Papaya, the herbaceous perennial plant is also known as Papaya melon tree, Pawpaw or papau, Kapaya, Lapaya, Papyas, Papye, Tapayas, and Fan mu gua. The entire papaya plant possesses various phytonutrients and can be considered for commercial, pharmaceutical, and industrial applications. The papaya plant is best with a large variety of phytonutrients and antioxidant, antimicrobial, and anti-dengue properties [4].

Phytochemicals are the natural, non-nutritive plant chemicals with defensive properties against cancer by protecting the cells from damage. Most of the phytochemicals possess the biological antioxidant capacity that protects our cells against the oxidative damage and reduces the risk of certain types of cancer. These phytochemicals tend to prevent the adhesion of pathogens to the human cell wall by physically binding to it. Some of the important phytochemicals found in C. papaya are Lycopene, Benzylglucosinolate, Beta-carotenoid, Benzylisothyocynate, chlorogenic acid, caffeic acid, protocatechuic acid, Quercetin, etc. [5,6].
Antioxidants are substances that prevent oxidative damage to the target molecule. An antioxidant can scavenge the free radicals because of their singlet oxygen quenching and redox hydrogen donating features. In recent days, the usage of synthetic antioxidants has been taken over by natural antioxidants as it could be safer without any side effects. In recent decades, due to the various pharmacological actions of the medicinal plants, many researchers are showing interest in studying the antioxidant phytochemicals such as phenols, flavonoids, and tannins which have been recognized for their potential role in preventing human diseases [7-10].

\section{METHODS}

Sample collection

Fresh leaves of $C$. papaya were collected from Mysuru and authenticated by the Department of Water and Health, JSS AHER, Mysore.

\section{Preparation of $C$. papaya leaf extract}

The collected plant materials were washed with running tap water to avoid surface contaminations and shade dried for about 15 days. The dried leaves were cut into small pieces and macerated into a fine powder; dried powder was soaked with different organic solvents such as hexane, ethyl acetate, methanol, and ethanol and was subjected to solvent extraction using the Soxhlet apparatus. Then, the extracted sample was stored at $4^{\circ} \mathrm{C}$ for further analysis.

Phytochemical analysis

Phytochemical screening was performed for the presence of alkaloids, carbohydrates, amino acids, glycosides, protein, phenolic compounds, and tannins from respective solvents such as hexane, ethyl acetate, methanol, and ethanol, according to standard procedure $[11,12]$. 


\section{Stock preparation}

$200 \mathrm{mg}$ of C. papaya extract was dissolved in $10 \mathrm{ml}$ of each solvent and $1 \mathrm{ml}$ of each solvent was used as a standard for various phytochemical tests.

\section{Alkaloids}

Wagner's test - For $1 \mathrm{ml}$ of the sample solution, few drops of Wagner's reagent were added along the sides of the test tube. The appearance of a reddish-brown precipitate indicates the presence of alkaloids [13].

\section{Carbohydrates}

Benedict's test - For $1 \mathrm{ml}$ of the sample solution, few drops of Benedict's reagent were added and heated for $2 \mathrm{~min}$. The appearance of a colored precipitate indicates the presence of carbohydrates.

Amino acids

Ninhydrin test - For $1 \mathrm{ml}$ of the sample solution, two drops of ninhydrin reagent were added. The formation of purple color indicates the presence of amino acids.

\section{Glycosides}

Kellar-Killiani test - For $1 \mathrm{ml}$ of sample solution $1 \mathrm{ml}$ of glacial acetic acid, few drops of ferric chloride and concentrated sulfuric acid were added. The appearance of a reddish-brown ring at the junction of liquids indicates the presence of glycosides [13].

\section{Phenolic compounds and tannins}

Ferric chloride test - For $1 \mathrm{ml}$ of extract, few drops of neutral $5 \%$ ferric chloride were added. The appearance of a dark green color indicates the presence of phenolic and tannin compounds.

\section{Protein}

Biuret test - For $1 \mathrm{ml}$ of extract, one drop of $2 \%$ copper sulfate and 1 $\mathrm{ml}$ of ethanol and potassium hydroxide were added. The presence of the pink color of the ethanolic layer indicates the presence of protein.

\section{Saponins}

For $1 \mathrm{ml}$ of extract, few drops of distilled water were added and shaken vigorously. The appearance of foam indicates the presence of saponins [13].

\section{Quinones}

For $1 \mathrm{ml}$ of extract, few drops of concentrated hydrochloric acid were added. The formation of a yellow precipitate indicates the presence of quinones.

Oxalate

For $1 \mathrm{ml}$ of extract, few drops of glacial acetic acid were added. The appearance of greenish-black coloration indicates the presence of oxalate.

\section{Anthocyanins}

For $1 \mathrm{ml}$ extract, $2 \mathrm{ml}$ of hydrochloric acid and $1 \mathrm{ml}$ of ammonia were added. The color change from pink-red to blue-violet indicates the presence of anthocyanins.

\section{Determination of total phenolic content (TPC)}

The TPC of the C. papaya sample was determined spectrophotometrically according to the Folin-Ciocalteu colorimetric method with slight modifications $[11,12]$

A standard solution of gallic acid was prepared using the distilled water in the concentration of $1 \mathrm{mg} / \mathrm{ml}$. Different working standards were prepared to obtain the standard calibration curve, followed by diluting with distilled water with $3 \mathrm{ml}$ and $0.5 \mathrm{ml}$ of FC reagent (1:1) and incubated at room temperature for about $15 \mathrm{~min}$, and then $2 \mathrm{ml}$ of $7 \%$ sodium carbonate was added. Similar steps were followed for estimating phenolic content in the sample extract and the absorbance was measured at $765 \mathrm{~nm}$ against blank using spectrophotometer. All experiments were made in triplicates and the TPC was determined using the standard gallic acid calibration curve.

\section{Determination of total flavonoid content (TFC)}

TFC of the C. papaya sample was determined spectrophotometrically according to the aluminum chloride method with slight modifications $[11,12]$.

A standard solution of quercetin was prepared using methanol in the concentration of $1 \mathrm{mg} / 1 \mathrm{ml}$. Different working standards were prepared to obtain a standard calibration curve using $1 \mathrm{ml}$ with methanol and 0.5 $\mathrm{ml}$ of $1.2 \% \mathrm{AlCl}_{3}, 0.5 \mathrm{ml}$ of sodium acetate and incubated for $30 \mathrm{~min}$. Similar steps were followed for estimating flavonoid content in the sample extract and absorbance was measured at $415 \mathrm{~nm}$ against blank using spectrophotometer. All determinations were made in triplicates and the TFC was determined using the standard quercetin calibration curve.

\section{Antioxidant assay}

2,2,1-Diphenyl-1-picrylhydrazyl (DPPH) radical scavenging activity $D P P H$

The free-radical scavenging activity was determined by DPPH proposed by Zadeh et al., 2008, with slight modifications [14].

A standard solution of ascorbic acid was prepared in the concentration of $2 \mathrm{mg} / \mathrm{ml}$ in methanol. The standard calibration curve was obtained using different working standards and was made up of $3 \mathrm{ml}$ with methanol. DPPH solution $(500 \mu \mathrm{l})$ was then added and mixed vigorously. Similar steps were followed for the sample extract. The reaction mixture was incubated for about $45 \mathrm{~min}$ in dark condition and absorbance was measured at $517 \mathrm{~nm}$ using a spectrophotometer. All determinations were made in triplicates and the standard curve was obtained using ascorbic acid.

The $\% \mathrm{DPPH}$ which was scavenged $\left(\% \mathrm{DPPH}_{\mathrm{sc}}\right)$ was calculated using the formula:

$$
\text { Scavenging effect }(\%)=1-\frac{\text { Absorbance of sample at } 517 \mathrm{~nm}}{\text { Absorbance of control at } 517 \mathrm{~nm}} \times 100
$$

\section{RESULTS}

Qualitative analysis conducted to evaluate the phytochemical profile of C. papaya leaves extract.

Phytochemical screening of C. papaya leaves extracts shows (Figs. 1-4), the presence of alkaloids, proteins, glycosides, phenol, tannin, saponin, quinine, oxalate, and anthocyanin. The presence of alkaloid, carbohydrate, glycoside, phenols, tannin, saponin, and oxalate shows the greater intensity of their presence in methanolic, ethanolic, hexane, and ethyl acetate extract (Table 1). In the methanolic extract, all the bioactive compounds such as alkaloids, glycosides, phenol, tannin, saponin, quinine, and oxalate are present expect proteins and anthocyanin.

The overall result shows that methanol extracts possess a greater number of bioactive compounds when compared to other solvents.

TPC

The total phenol content was determined by Folin-Ciocalteu method and reported as gallic acid equivalents (GAE) concerning the standard curve. The standard taken was gallic acid in a concentration of $1 \mathrm{mg} / \mathrm{ml}$. The concentration of sample extract was evaluated by comparing it to the standard Graph 1. The concentration of TPC presents in the leaf extract of C. papaya in methanol extract is $13.7 \mathrm{mgGAE} / \mathrm{g}$ and hexane extract is 13.6 $\mathrm{mgGAE} / \mathrm{g}$, ethanol extract is $13.5 \mathrm{mgGAE} / \mathrm{g}$, and ethyl acetate extract is $9.486 \mathrm{mgGAE} / \mathrm{g}$, respectively, to the GAE of the sample [Table 2] 
Table 1: Qualitative analysis of Carica papaya leaves extract: Phytochemical screening

\begin{tabular}{|c|c|c|c|c|c|c|c|c|c|c|c|}
\hline S. No. & Sample & Alkaloid & Carbohydrate & $\begin{array}{l}\text { Amino } \\
\text { acid }\end{array}$ & Glycoside & $\begin{array}{l}\text { Phenols } \\
\text { tanin }\end{array}$ & Proteins & Saponin & Quinine & Oxalate & Anthocyanin \\
\hline 1. & Methanol & + & + & + & + & + & - & + & + & + & - \\
\hline 2. & Ethanol & + & + & - & + & + & - & + & + & - & - \\
\hline 3. & Hexane & + & + & - & - & + & - & - & - & + & - \\
\hline 4. & Ethyl acetate & + & + & - & - & - & - & + & - & - & - \\
\hline
\end{tabular}

Table 2: Quantification of TPC and TFC in different solvent extracts of Carica papaya leaves

\begin{tabular}{llll}
\hline S. No. & Solvent & TPC & TFC \\
\hline 1. & Methanol & $0.083 \pm 0.003$ & $0.392 \pm 0.006$ \\
2. & Hexane & $0.078 \pm 0.006$ & $0.445 \pm 0.025$ \\
3. & Ethyl acetate & $0.071 \pm 0.004$ & $0.422 \pm 0.02$ \\
4. & Ethanol & $0.061 \pm 0.002$ & $0.196 \pm 0.08$ \\
\hline
\end{tabular}

TPC: Total phenolic content, TFC: Total flavonoid contents

TFC

The TFC was determined by aluminum chloride method and represented as quercetin equivalents (QAE) concerning the standard curve. The standard taken was quercetin in a concentration of $1 \mathrm{mg} / \mathrm{ml}$. The concentration of sample extract was evaluated by comparing it to the standard Graph 2.

The concentration of flavonoids presents in the leaf extract of C. papaya in methanol extract is $21.60 \mathrm{mgQAE} / \mathrm{g}$, hexane extract is $26.48 \mathrm{mgQAE} / \mathrm{g}$, ethyl acetate extract is $27 \mathrm{mgQAE} / \mathrm{g}$, and ethanol extract is $15.65 \mathrm{mgQAE} / \mathrm{g}$ extract, respectively, to the QAE of the sample [Table 2].

\section{Antioxidant activity of $C$. papaya}

DPPH assay DPPH radical scavenging activity

$\mathrm{IC}_{50}$ (Inhibitory Concentration) of the sample extract was determined by comparing it to the standard value of ascorbic acid. The result of the antioxidant activity of $C$. papaya with methanolic extract by DPPH assay shows that the presence of free radicals is more and directly proportional to the concentration of the sample. It means higher the concentration higher will be the percentage of free radicals in the C. papaya leaves methanolic extract.

The Graph 3 indicates that the percentage of radical scavenging activity of the methanolic extracts at different concentrations with $50 \%$ of DPPH scavenging activity was found to be $80 \mu \mathrm{g} / \mathrm{ml}$, as the concentration of the sample extract was evaluated compared to the standard value. The results show that methanolic solvent extracts analyzed for the DPPH scavenging activity show the higher radical inhibition activity which can be comparable to standard ascorbic acid.

\section{DISCUSSION}

Medicinal plants constitutes as an important natural wealth of the country by playing a significant role in primary health of mankind. They importantly serve as raw material for manufacturing medicines as therapeutic drugs [15]. C. papaya is used as a natural medicinal plant, recognized for its antimicrobial, anti-amoebic, antifungal, and hypolipidemic activity. Mainly papaya is recognized as "King of medicine," due to the presence of a large number of important phytonutrients loaded in it, and also referred to as "Powerhouse of nutrients" [16,17].

The plant based medicines which have been used in treatment from ancient times reveals in some cases desirable effect were not achieved because the biological action of the herbal medicine of phytoconstituents may vary, as well as the amount of phytoconstituent in a plant can vary according to the age of plant, time of collection, and also environmental conditions [18]

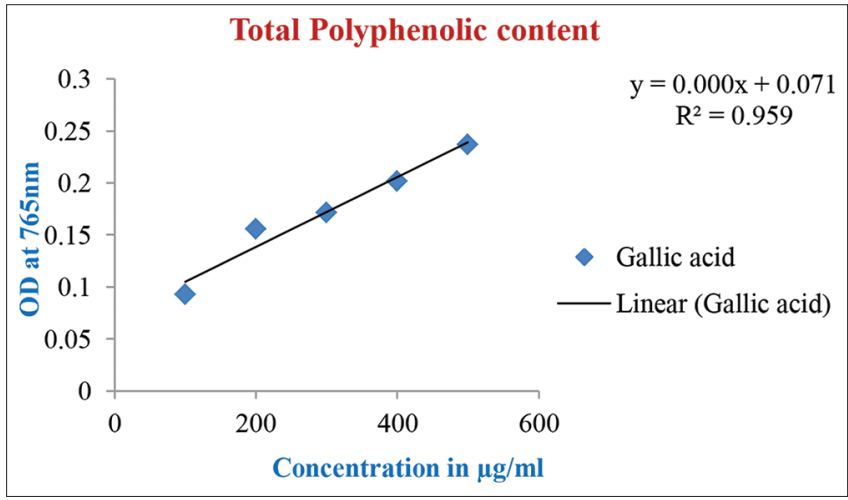

Graph 1: Standard gallic acid calibration curve. (Values are expressed as mean $\pm \mathrm{SE} \mathbf{m g}$ of gallic acid equivalent per gram of dry weight, that is, GAE/g of the extract triplicates of each sample extract was recorded)

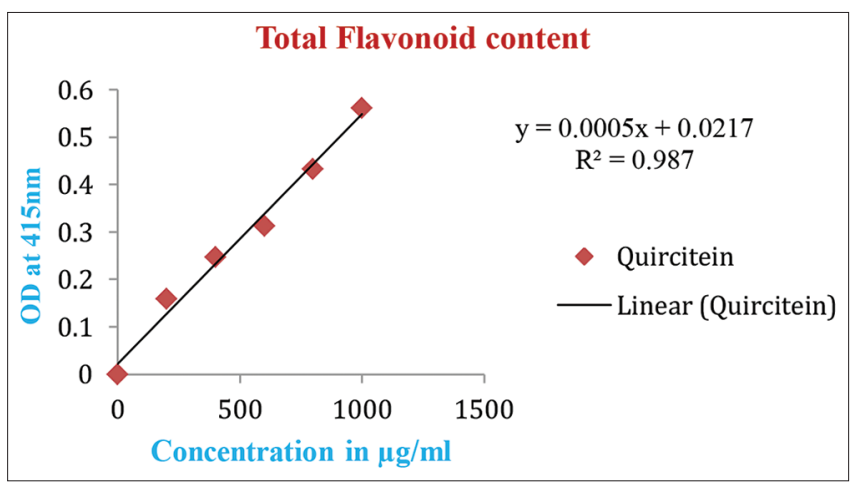

Graph 2: Standard quercetin calibration curve. (Values are expressed as mean $\pm S E$ mg of quercetin equivalent per gram of dry weight, that is, QAE/g of the extract triplicates of each sample extract was recorded)

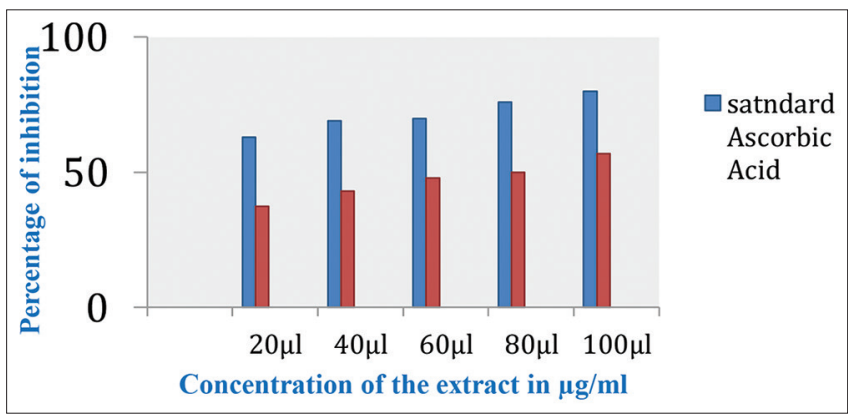

Graph 3: 2,2,1-Diphenyl-1-picrylhydrazyl scavenging activity of methanolic extracts of Carica papaya leaves. (Values are expressed as mean $\pm S E \mathrm{mg}$ of ascorbic acid per gram of dry weight, that is, extract triplicates of each sample extract were recorded)

An attempt to study the in vitro antioxidant, antimicrobial, and antiinflammatory of $C$. papaya seed extract with methanolic fractions, 


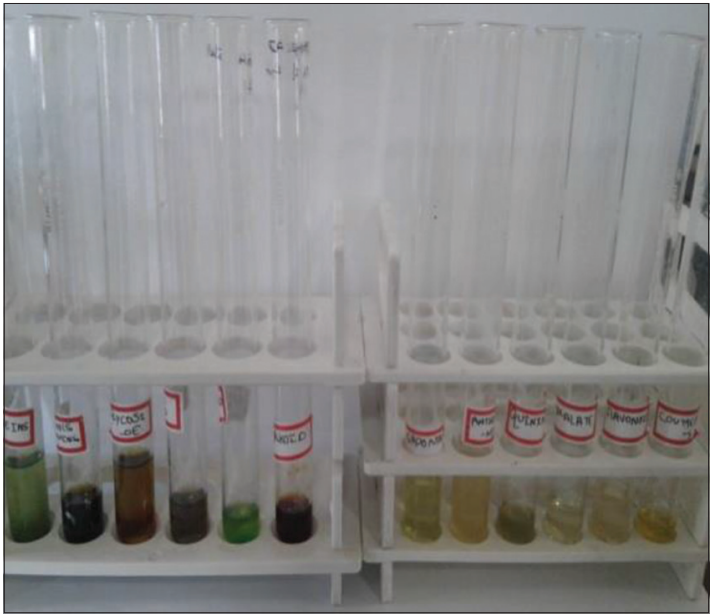

Fig. 1: Phytochemical analysis of ethanol extract

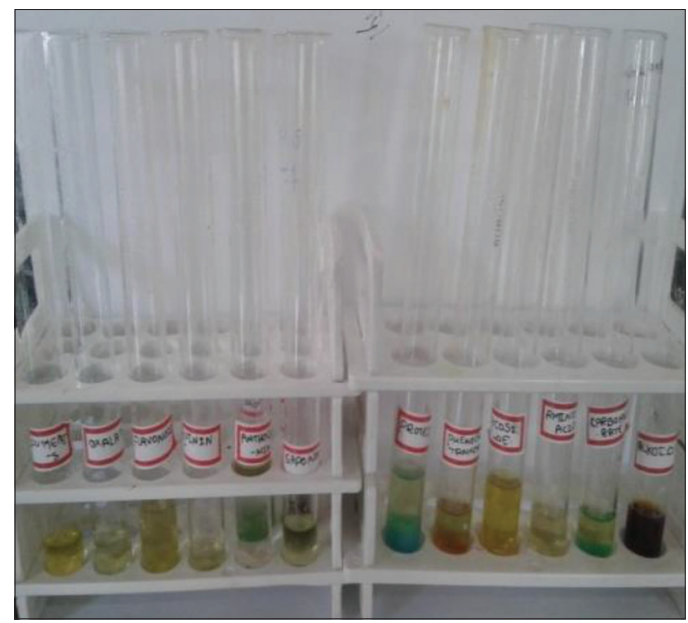

Fig. 2: Phytochemical analysis of ethyl acetate

revealed the TPC and the TFC in the methanolic fraction was high compared to other solvent extracts, the antioxidant activity showed the radical scavenging activity of methanolic extracts at different concentration with $50 \%$ of scavenging activity, a comparison of the ability of various seed extract have proved their limited DPPH scavenging activity compared to methanol [19].

The antioxidant activity was conducted to compare the total antioxidant activity, TPC, and TFC from the different parts of the papaya tree including their ripe and unripe fruit, seeds, and the young leaves. The result showed that the highest antioxidant activity through $\beta$ carotene assay was observed in unripe fruit $(90.67 \pm 0.29 \%)$, followed by young leaves, ripe fruit, and the seed. In brief, taken to account all the parameter measured, antioxidant was highly remarkable in the sequence of young leaves $>$ unripe fruit $>$ seed [20].

The investigation reports of quantitative analysis of total phenolic and TFCs in extracts of Oroxylum indicum L. Kurz. reveal that the TPC and TFC varied among the different solvent extracts used and among them methanolic extracts of seed showed the highest amount compared to other solvent extracts and insists their ratio and distribution in different parts of the tree that could be used for treating various ailments [2].

An increase in the demand for the natural bioactive compounds from the medicinal plants has provided an opportunity for the extraction of either pure or standardized extracts for various therapeutic activities. C. papaya leaves are a boon from nature for food as well as therapeutic applications.

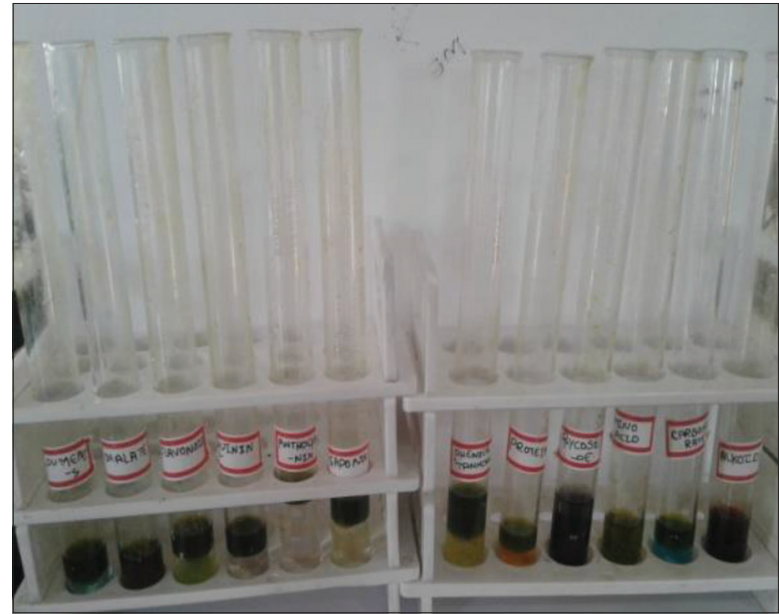

Fig. 3: Phytochemical analysis of hexane extracts

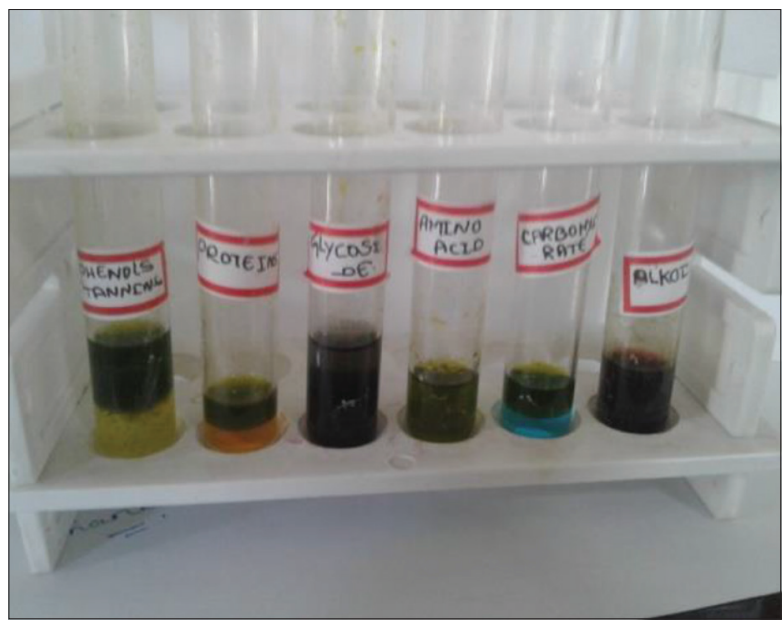

Fig. 4: Phytochemical analysis of methanol extract

\section{CONCLUSION}

Bioactive compounds can be studied by extraction and isolation, also with defining their structure and by analyzing it in laboratory models as in vitro and in vivo studies and importance was given for identification and characterization of the specific phytochemical which is primarily responsible for biological activity.

The current study which was aimed at investigating the presence of biologically active phytochemicals and antioxidant properties of $C$. papaya leaves extract reveals that samples with various solvents such as methanol, ethanol, hexane, and ethyl acetate have shown the presence of phytochemicals constituents such as alkaloid, carbohydrates, and amino acids.

Among the used solvent extracts, the C. papaya leaves with methanolic fraction showed the presence of more phytochemicals and have effective phenolic, flavonoid content, and exhibited strongest antioxidant properties which can effectively scavenge reactive oxygen species compared to other solvent extracts used.

Hence, C. papaya can be considered as an important and potential natural source for various pharmaceutical and medicinal applications. Interestingly, the broad spectrum of phytochemicals and antioxidants presents in them can be regarded as the reservoir of naturally occurring diverse bioactive molecules and papaya as herbal medicine can be furnished for the quantitative and qualitative extraction for exploring the new promising biomolecules for pharmaceutical applications. 


\section{AUTHOR CONTRIBUTION}

Nandini G and Kanthesh BM conceptualized the study. Nandini G and Nagalambika Prasad conducted the experiments. Nandini G drafted the Manuscript. Gopenath G and Murugesan Karthikeyan, Ashok Gnanasekaran, Ranjith MS, and Pradeep Palanisamy helped with the Manuscript and Discussion.

\section{DECLARATION AND COMPETING INTEREST}

The authors declare that there are no conflicts of interest.

\section{ACKNOWLEDGMENT}

The authors would like to acknowledge the Management of JSS Academy of Higher Education and Research, Mysuru, Karnataka, for supporting the basic research ideas and also for the resources provided.

\section{REFERENCES}

1. Makkar HP, Norvsambuu T, Lkhagvatseren S, Becker K. Plant secondary metabolites in some medicinal plants of Mongolia used for enhancing animal health and production. Tropicultura 2009;27:159-67.

2. Samatha T, Shyamsundarachary R, Srinivas P, Swamy NR. Quantification of total phenolic and total flavonoid contents in extracts of Oroxylum indicum L. Kurz. Asian J Pharm Clin Res 2012;5:177-9.

3. Krishna KL, Paridhavi M, Patel JA. Review on nutritional, medicinal and pharmacological properties of Papaya (Carica papaya Linn.). Nat Prod Radiance 2008;7:364-73.

4. Abd Elgadir M, Salama M, Adam A. Carica papaya as a source of natural medicine and its utilization in selected pharmaceutical applications. Int J Pharm Sci 2014;6:880-4.

5. Parle M, Gurditta A, Basketful benefits of papaya. Int Res J Pharm 2011;2:6-12

6. Ayoola PB, Adeyeye A. Phytochemical and nutrient evaluation of Carica papaya (Pawpaw) leaves. Int J Recent Res Appl Stud 2010;5:325-8.

7. Basalingappa KM, Anitha B, Raghu N, Gopenath TS, Karthikeyan M,
Gnanasekaran A, et al. Medicinal uses of Carica papaya. J Nat Ayurvedic Med 2018;2:000144.

8. Meenakshi S, Umayaparvathi S, Arumugam M, Balasubramanian T. In vitro antioxidant properties of FTIR analysis of two sea weeds of Gulf of Mannar. Asian Pac J Trop Biomed 2011;1:S66-70.

9. Jaiswal P, Kumar P, Singh VK, Singh DK. Carica papaya Linn: A potential source for various health problems. J Pharm Res 2010;3:9981003.

10. Wu YY, Li W, Xu Y, Jin EH, Tu YY. Evaluation of the antioxidant effects of four main theaflavin derivatives through chemiluminescence and DNA damage analyses. J Zhejiang Univ Sci B 2011;12:744-51.

11. Ghosal M, Mandal PA. Phytochemical screening and antioxidant activities of two selected "bihi" fruits used as vegetables in Darjeeling Himalaya. Int J Pharm Pharm Sci 2012;4:567-74.

12. Nounagnon MS, Dah-Nouvlessounon D, Ntcha C, Legba B, BabaMoussa F, Adjanohoun A, et al. Phytochemistry and biological activities of Crateva adansonii extracts. Int J Pharm Pharm Sci 2018;10:62-7.

13. Soni A, Sosa S. Phytochemical analysis and free radical scavenging potential of herbal and medicinal plant extracts. J Pharmacogn Phytochem 2013;2:22-9.

14. Ebrahimzadeh MA, Hosseinimehr SJ, Hamidinia A. Antioxidant and free radical scavenging activity of Feijoa sallowiana fruits peel and leaves. Pharmacologyonline 2008;1:7-14

15. Rupeshkumar M, Kavitha K, Haldar PK. Role of herbal plants in the diabetes mellitus therapy: An overview. Int J Appl Pharm 2014;6:1-3.

16. Ainsworth EA, Gillespie KM. Estimation of total phenolic content and other oxidation substrates in plant tissues using Folin-Ciocalteu reagent. Nat Protoc 2007;2:875-7.

17. Nandini G, Basalingappa KM. A review on significance of Carica papaya Linn: A promising medicinal plant. Int J Recent Sci Res 2019;11:37602-7.

18. Verma H, Prasad SB, Yashwant SH. Herbal drug delivery system: A modern era prospective. Int J Curr Pharm Rev Res 2013;4:88-101

19. Pooja G Singh, Basalingappa KM. In vitro antioxidant, antiinflammatory and anti-microbial activity of Carica papaya seeds. Glob J Med Res 2020;20:1-21

20. Maisarah AM, Amira BN, Asmah R, Fauziah O. Antioxidant analysis of different parts of Carica papaya. Int Food Res J 2013;20:1043-8. 